Running head: The Structure of Peritraumatic Reactions

Journal of Abnormal Psychology (2021). doi:10.1037/abn0000663

\title{
The Structure of Peritraumatic Reactions and their Relationship with PTSD among Disaster Survivors
}

\author{
Alessandro Massazza ${ }^{1}$, Helene Joffe ${ }^{1}$, Philip Hyland ${ }^{2}$, and Chris R. Brewin ${ }^{1}$ \\ ${ }^{1}$ Department of Clinical, Educational and Health Psychology, \\ University College London, London, U.K. \\ ${ }^{2}$ Department of Psychology, National University of Ireland, Maynooth, Ireland
}

\section{Author Note}

Correspondence concerning this article should be addressed to Chris R. Brewin, University College London, Research Department of Clinical, Educational and Health Psychology, 26 Bedford Way, London WC1H0AP. Email: c.brewin@ucl.ac.uk 


\begin{abstract}
Peritraumatic reactions such as fear, psychic and somatoform dissociation, tonic immobility, data-driven processing, and mental defeat are important in the etiology of posttraumatic stress disorder (PTSD). However current measures of such reactions overlap conceptually and do not clearly identify distinct peritraumatic processes. It is not known which processes are uniquely associated with PTSD. We investigated the factor structure of six standard peritraumatic measures and their relationship with the four DSM-5 PTSD symptom clusters. Measures were administered to 308 earthquake survivors with high levels of exposure to traumatic events. Items comprising the six measures were investigated using exploratory structural equation modeling, which identified five peritraumatic response factors. Items from most measures loaded on multiple factors. The factors labeled Mental Defeat and Somatoform Dissociation significantly predicted all PTSD symptom clusters. The factor labeled Cognitive Overload significantly predicted Intrusions, Avoidance, and Alterations in Arousal and Reactivity. The factor labeled Immobility significantly predicted Intrusions and Avoidance while Distress significantly predicted Negative Alterations in Cognition and Mood and Alterations in Arousal and Reactivity. Due to the key role such reactions play in the development of PTSD, the findings are likely to benefit the study of etiological mechanisms, the prediction of those at greatest risk, and the design of preventative interventions.
\end{abstract}

\title{
General Scientific Summary
}

How a person feels, thinks, and behaves during a traumatic event, i.e., the peritraumatic response, can play an important role in determining whether they develop posttraumatic stress disorder (PTSD). However, it is not known how many distinct peritraumatic responses there are and how they are associated with PTSD. We analysed six commonly-used measures 
The Structure of Peritraumatic Reactions 3

of peritraumatic response given to a sample of earthquake survivors and found five distinct underlying factors, which showed distinct patterns of association with different symptom clusters of PTSD.

Keywords: trauma; disaster; earthquakes; PTSD; dissociation; peritraumatic 
The systematic study of peritraumatic reactions (i.e., transient feelings, thoughts, and behaviors that take place either during or immediately after exposure to trauma) principally began with the studies by Marmar and colleagues (Marmar, Weiss, Metzler, Ronfeldt, \& Foreman, 1996; Marmar et al., 1994) and received further impetus with the inclusion of Criterion A2 (i.e., the specification that traumatic experiences had to be accompanied by intense feelings of fear, helplessness, and horror) in the DSM-IV posttraumatic stress disorder (PTSD) diagnosis (American Psychiatric Association, 1994). Since then peritraumatic phenomena have been found to be strong predictors of the risk of developing PTSD following a traumatic event (Bovin \& Marx, 2011), and are of considerable clinical and theoretical importance.

There are a number of peritraumatic scales that measure psychological, physiological, and somatic reactions but many of these contain overlapping items and how the contents of the scales relate to one another is not known. There is an urgent need to understand how many distinct and robust peritraumatic reactions exist and to determine which of these is central in predicting the risk of developing PTSD. The following sections will introduce the key peritraumatic phenomena that have been most studied in the literature on PTSD (Gorman, Engel-Rebitzer, Ledoux, Bovin, \& Marx, 2016). Current limitations will be outlined followed by our research questions.

\section{Different Types of Peritraumatic Response}

Peritraumatic dissociation (psychic). Dissociation is a complex phenomenon that encompasses several components including depersonalization, derealization, amnesia, and identity confusion or alteration (Bryant, 2007; Cardeña, 1994; van der Hart, Nijenhuis, Steele, \& Brown, 2004). Peritraumatic dissociation has been defined (Marmar, Metzler, \& Otte, 2004) as alterations "in the sense of self, time, place, and meaning, which confer a sense of unreality to the event as it is occurring" (p. 146). Meta-analyses on PTSD risk factors have 
reported that peritraumatic dissociation is a strong predictor of PTSD with a weighted $r$ in the range 0.35 - 0.40 (Lensvelt-Mulders et al., 2008; Ozer, Best, Lipsey, \& Weiss, 2003).

However, caution has been advised in interpreting such findings due to several methodological differences and shortcomings across heterogeneous studies, together with theoretical and conceptual complexities in defining and measuring peritraumatic dissociation (van der Hart, van Ochten, van Son, Steele, \& Lensvelt-Mulders, 2008).

Peritraumatic distress. Substantial evidence supports the link between psychological distress at the time of the trauma and the subsequent development of PTSD (Brewin, Andrews, \& Rose, 2000; Vance, Kovachy, Dong, \& Bui, 2018). Peritraumatic distress now includes emotions such as anger, shame, and guilt (Andrews, Brewin, Rose, \& Kirk, 2000), threats to physical safety or thoughts of death (March, 1993), panic (Adams \& Boscarino, 2011), and a variety of physiological signs of arousal including shaking, increased heart rate, and loss of bowel and bladder control (Solomon, Laor, \& McFarlane, 1996). A meta-analysis on the relationship between peritraumatic distress and PTSD symptoms found a significant weighted $r=0.55$ (Thomas, Saumier, \& Brunet, 2012).

Peritraumatic dissociation (somatoform). Somatoform dissociation is a concept derived from studies of physical responses to threat in animals such as "playing dead" (Nijenhuis, Vanderlinden, \& Spinhoven, 1998). It was defined as specifically involving the body and comprising a partial or complete loss of perception, such as paralysis, analgesia, and anaesthesia, as well as more active involuntary responses such as distortions in the visual field or ataxia (Nijenhuis, van der Hart, Kruger, \& Steele, 2004).

Tonic immobility. Tonic immobility is the last step within the defence cascade, taking place after freezing, flight, and fight, when escape or resistance has been unsuccessful. It is characterized by catatonic-like motionless posture, suppressed vocal behavior, analgesia, intermittent periods of eye closure, fixed, unfocused stare or gaze, Parkinsonian-like tremors 
in the extremities, and waxy flexibility, together with sympathetic and parasympathetic reactions (Gallup \& Rager, 1996). Tonic immobility has been extensively assessed in rape survivors (Kalaf et al., 2017) but recent evidence highlights its presence in a variety of different traumas characterized by situations in which escape or resistance is not possible (Hagenaars, 2016). In retrospective studies higher levels of tonic immobility at the time of the trauma were found to be associated with subsequent PTSD (Kalaf et al., 2015).

Data-driven processing. Data-driven processing has been defined as a bottom-up information processing style characterized by a disproportionate processing of sensory/perceptual stimuli (Halligan, Clark, \& Ehlers, 2002). The concept was first applied to PTSD by Ehlers and Clark (2000), who proposed that intrusive memories result from excessive data-driven processing at the time of the trauma, resulting in poorly elaborated memories that are insufficiently integrated with other autobiographic knowledge. Data-driven processing has been associated with higher levels of intrusive memories and PTSD (Ehring, Ehlers, \& Glucksman, 2008; Halligan et al., 2002; Halligan, Michael, Clark, \& Ehlers, 2003).

Mental defeat. Mental defeat is an extreme form of powerlessness in which individuals lose their sense of being human and cease caring about whether they are going to live or die (Dunmore, Clark, \& Ehlers, 1999, 2001). Mental defeat has been found to predict PTSD symptom trajectories in prospective studies up to 6 to 9 months following trauma (Dunmore et al., 2001; Freeman et al., 2013; Kleim, Ehlers, \& Glucksman, 2012). Studies to date have mostly focused on assault survivors (Dunmore et al., 1999, 2001), survivors of political imprisonment (Ehlers, Maercker, \& Boos, 2000), and on post-conflict contexts (Wilker et al., 2017).

\section{Inter-Relationship of Peritraumatic Reactions}

There is little consensus concerning how these responses relate to one another. Most attention has been paid to the relationships between peritraumatic distress and peritraumatic 
dissociation. Correlations between them tend to be in the range of $0.5-0.7$ (Brunet et al., 2001; Bui et al., 2011; Kannis-Dymand, Carter, Lane, \& Innes, 2019). In some cases, the association between peritraumatic dissociation and PTSD has been found to significantly decrease when peritraumatic distress is also included as a predictor (van der Hart et al., 2008). However, other studies have found peritraumatic distress to predict PTSD even after dissociation was entered in the model (Birmes et al., 2005; Bui et al., 2010; Moss et al., 2017). Some have argued that peritraumatic dissociation is a mediator of the relationship between peritraumatic distress and PTSD (Otis, Marchand, \& Courtois, 2012) or that peritraumatic distress is a trigger for peritraumatic dissociation (Fikretoglu et al., 2006).

Tonic immobility and peritraumatic dissociation have also been found to be positively associated (Fusé, Forsyth, Marx, Gallup, \& Weaver, 2007; Marx, Forsyth, Gallup, Fusé, \& Lexington, 2008). In one study (Abrams, Carleton, \& Asmundson, 2012) tonic immobility did not predict PTSD severity after peritraumatic dissociation and trait anxiety were controlled for.

One paper assessed the relationship between somatoform and psychic dissociation and found a strong positive correlation of $r=.62$ (Nijenhuis, van Engen, Kusters, \& van der Hart, 2001). In a prospective study, somatoform dissociation and psychic dissociation both predicted PTSD at 6 months, but not when initial PTSD numbing was controlled for (Hagenaars, van Minnen, \& Hoogduin, 2007).

A significant problem with this literature is that few studies have included more than one or two measures of peritraumatic responding. The high correlations typically obtained between them may reflect overlap in items belonging to different scales. Moreover, individual measures are often composed of a number of factors, some of which overlap conceptually with other measures (Hagenaars, 2016). It is, therefore, unknown how many separate constructs are needed to account for the variety in peritraumatic responding, and 
how these constructs are associated with PTSD. It is likely that peritraumatic responding is associated with specific symptom clusters, such as intrusions or alterations in arousal and reactivity.

\section{Research Questions}

In this study, we assessed the latent structure of items from representative scales measuring each of the six peritraumatic reactions reviewed above to determine the optimal latent structure of peritraumatic responses. We used exploratory structural equation modelling (ESEM) (Asparouhov \& Muthén, 2009) to determine (1) the optimal number of latent factors to be extracted, and (2) their association with the four constituent symptom clusters of PTSD (Intrusions, Avoidance, Negative Alterations in Cognition and Mood [NACM], and Alterations in Arousal and Reactivity) described in DSM-5 (American Psychiatric Association, 2013).

\section{Methods}

\section{Participants and Recruitment}

All participants were survivors of the 2016-2017 Central Italy earthquakes. On the 24th of August, 2016 a $6.0 \mathrm{M}_{\mathrm{w}}$ earthquake struck Central Italy, destroying the majority of buildings in Amatrice, Accumoli, and Arquata del Tronto. The vast majority of the deaths, 238 out of 299, were registered in Amatrice (population 2,500), the hamlet where the research took place. Further powerful shocks struck Central Italy during this period, the last being on the 18th January 2017.

A purposive sample of 341 participants was identified, building on a previous study conducted in the area by the authors (Massazza, Joffe, \& Brewin, 2019), and with the aid of the health centre and the local municipality. Participants were contacted individually by telephone or face-to-face to generate a sample that was approximately representative of the population as whole in terms of age and gender as per 2016 census data (Istituto Nazionale di 
Statistica, 2016). Of the 341 individuals contacted, 308 agreed to participate (90\% response rate).

\section{Measures}

All measures were answered in respect of the earthquakes to which participants had been exposed.

Mental Defeat Questionnaire (MDQ) (Dunmore et al., 1999). The MDQ is an 11item self-report questionnaire that asks participants to retrospectively rate the extent to which they experienced mental defeat (e.g., helplessness, de-humanization) during the trauma from 0 "not at all/never" to 4 "very strongly" (example item "I felt destroyed as a person"). Scores can range from $0-44$ with higher scores indicating more mental defeat. The internal reliability of the scale scores in this sample was excellent $(\alpha=.89)$.

\section{Somatoform Peritraumatic Dissociation Questionnaire (SDQ-P) (Nijenhuis \&}

van der Hart, 1998). The SDQ-P is a 11-item self-report questionnaire which asks participants to retrospectively rate the extent to which they experienced somatoform dissociation reactions (e.g., distortions in body perception or unusual bodily experiences) during the trauma from 1 "not at all" to 5 "extremely" (example item "It felt as if my body, or parts of it, disappeared"). Participants specify whether the reaction might have been due a physical cause (e.g., medical condition, being physically restrained). Scores can range from $11-55$ with higher scores indicating more dissociation. Internal reliability of the scale scores was excellent $(\alpha=.83)$.

\section{Peritraumatic Dissociative Experiences Questionnaire (PDEQ) (Marmar, Weiss,} \& Metzler, 1997). The PDEQ is a 10-item self-report questionnaire which asks participants to retrospectively rate the extent to which they experienced a series of dissociative reactions (e.g., derealization, depersonalization, distortions in sense of time etc.) during the trauma from 1 "not at all true" to 5 "extremely true". Example item: "What was happening seemed 
unreal to me, like I was in a dream, or watching a movie or play”. Scores can range from 10 -50 with higher scores indicating more dissociation. Internal reliability of the scale scores was excellent $(\alpha=.89)$.

Tonic Immobility Scale (TIS) (Forsyth, Marx, Fusé, Heidt, \& Gallup, 2000). The TIS is a 10-item self-report questionnaire which asks participants to retrospectively rate the extent to which they experienced tonic immobility (e.g., paralysis, suppressed vocal behavior etc.) during the trauma from 0 "not at all" to 6 "extremely". Example item "Rate the degree to which you froze or felt paralyzed during your most recent experience”. Scores can range from $0-60$ with higher scores indicating more immobility. Internal reliability of the scale scores was excellent $(\alpha=.87)$.

Peritraumatic Distress Inventory (PDI) (Brunet et al., 2001). The PDI is a 13-item self-report questionnaire which asks participants to retrospectively rate the extent to which they experienced distress (e.g., negative emotions or perceptions of life threat) during the trauma from 1 "not at all true" to 5 "extremely true" (example item "I thought I might die"). Scores can range from $13-65$ with higher scores indicating more distress. Internal reliability of the scale scores was excellent $(\alpha=.82)$.

Data-Driven Processing Scale (DDPS) (Halligan et al., 2002). The DDPS is an 8item self-report questionnaire that asks participants to retrospectively rate the extent to which they experienced data-driven processing (e.g., disproportionate perceptual processing) during the trauma from 0 "not at all" to 4 "very strongly" (example item "I was overwhelmed by sensations and couldn't put everything together"). Scores can range from $0-32$ with higher scores indicating more data-driven processing. Internal reliability of the scale scores was excellent $(\alpha=.91)$.

PTSD symptom clusters. Participants also completed the PTSD Checklist for DSM5 (PCL-5), a 20-item self-report measure assessing the 20 symptoms of PTSD (Weathers et 
al., 2013). The rating scale ranges from 0 ('not at all') to 4 ('extremely') focusing on how bothered the individual was by the symptoms in the last month. The PCL-5 has been shown to have high total internal reliability $(\alpha=.90)$ and acceptable to good internal reliability for the subscales Intrusions, Avoidance, NACM, and Alterations in Arousal and Reactivity ( $\alpha$ range $=.57-.78)($ Sveen, Bondjers, \& Willebrand, 2016). Internal reliability of the overall scale scores in the current sample was excellent $(\alpha=.94)$.

Finally, participants answered a series of demographic questions investigating traumatic exposure, gender, age, level of education, religious affiliation, and residency.

\section{Procedure}

All questionnaires went through a thorough back-translation procedure. As the only measure without an official English translation, the SDQ-P was first translated from Dutch into English with the aid of a native-speaking expert in peritraumatic reactions. Then all measures were translated from English to Italian by the first author. The Italian translations were then given to a second translator fluent in both Italian and English who translated the measures back into English blind to the original versions. The original English version and the back-translated English version were then compared, and discrepancies resolved.

Data collection took place for three months in May, June, and July 2018. This was 20 months following the earthquake in August 2016 and 15 months following the last major earthquake in January 2017. The UCL Research Ethics Committee approved this research with the project ID: $10517 / 001$. The project was also approved by the national health service center of Rieti and by the local municipality, Comune di Amatrice. Prior to taking part participants read an information sheet and provided written informed consent.

\section{Data analysis}

Descriptive statistics were calculated for all demographic and earthquake exposure variables, peritraumatic reactions, and PTSD scores. ESEM was performed to determine the 
optimal number of latent factors to extract to explain the covariance between the 63 items making up the six peritraumatic measures, and to model the associations between these factors and the PTSD symptom clusters. All analyses were performed using Mplus version 8.2 (Muthén \& Muthén, 2017). The peritraumatic experience factors were modeled as the predictor variables and the four PTSD symptom clusters were modeled as the criterion variables. The four-factor model of PTSD produced acceptable model fit $\left(\chi^{2}(164)=445.62\right.$, $p<.001 ; \mathrm{CFI}=.97 ; \mathrm{TLI}=.96 ; \mathrm{RMSEA}(90 \% \mathrm{CI})=.08(.07, .08) ; \mathrm{SRMR}=.05)$.

ESEM models with one to seven factors were estimated, and because the peritraumatic experience indicators are ordered categorical in nature, the Weighted Least Squares Mean- and Variance-adjusted (WLSMV) estimator was used (Flora \& Curran, 2004). The models were estimated using Geomin rotation meaning the extracted factors were free to correlate. There was minimal missing data $(n=1)$ and this was managed using the default pairwise deletion method. Assessment of model fit followed standard guidelines (Hu \& Bentler, 1999) where acceptable fit is indicated by a non-significant chi-square test $\left(\chi^{2}\right)$, Comparative Fit Index (CFI) and Tucker Lewis Index (TLI) values $\geq .90$, and Root Mean Square Error of Approximation (RMSEA) and Standardized Root Mean Square Residual $(\mathrm{SRMR})$ values $\leq .08$. The $\chi^{2}$ test produces inflated Type 1 errors, therefore model fit and model comparisons should not rely solely on this index (Tanaka, 1987). In an ESEM context, overall model fit improves with increasing numbers of extracted factors, therefore, determining the optimal factorial solution was made on the basis of several criteria. Statistically, we inspected the change in the TLI value ( $\Delta$ TLI) for each model compared to the model with one less factor extracted. The $\Delta$ TLI value is superior to the more commonly used $\triangle \mathrm{CFI}$ value because the TLI contains a penalty for increasing model complexity. Chen and colleagues (Chen, Curran, Bollen, Kirby, \& Paxton, 2008) recommend that changes $\geq$ .010 reflect significant improvement in model fit. Additionally, all models were estimated 
using the Maximum Likelihood estimator to generate BIC values which can be used to compare nested and non-nested models. The model with the lowest BIC value should be favored, and a change of ten points represents strong evidence in favor of the model with the lower BIC value (Raftery, 1995). In addition to these considerations, model selection was guided by inspection of the model parameters and the interpretability of the extracted factors.

\section{Results}

\section{Descriptive Statistics}

The majority of participants were from Amatrice $(n=274)$, with a minority from other adjoining municipalities hit by the earthquakes $(n=34)$. The mean age of respondents (41\% male, $59 \%$ female) was 47.65 years ( $S D$ 16.54, range $=18-81$ years). All identified as Caucasian, and $84 \%$ as Catholic. Education levels ranged from primary school diploma (9\%), middle school diploma (25\%), secondary school diploma (52\%), to university degree $(14 \%)$. Average subjective earthquake intensity as measured on an 11-point scale from 0 ('not intense at all') to 10 ('extremely intense') was 9.1 (SD 1.74). Most participants (78\%, $n=$ 243) had lost their house due to the earthquakes, with $35 \%(n=109)$ losing a family member, 44\% losing close friends $(n=138)$, and everybody losing acquaintances. Participants also reported being exposed to gruesome scenes such as corpses or body parts (37\%), hearing voices of people asking for help from under debris (42\%), witnessing someone dying in front of them (16\%), and having injuries requiring urgent medical support (15\%).

The mean and standard deviation of scores on the six peritraumatic measures were as follows: Mental Defeat Questionnaire $(M=10.53, S D=9.88)$; Somatoform Peritraumatic Dissociation Questionnaire $(M=20.24, S D=8.75)$; Peritraumatic Dissociative Experiences Questionnaire $(M=24.71, S D=10.11)$; Tonic Immobility Scale $(M=23.78, S D=15.23)$; Peritraumatic Distress Inventory $(M=36.63, S D=10.01)$; Data-Driven Processing Scale $(M$ 
$=16.18, S D=9.13)$. The mean score on the PCL-5 was $24.82(S D=18.19)$, and 92 participants (29\%) exceeded the suggested clinical cut off score of 33 (Bovin et al., 2016).

\section{Factor Structure}

The ESEM model fit results are presented in Table 1. All models with the exception of the one-factor model met minimum criteria for acceptable model fit. The $\Delta$ TLI supported the extraction of five latent peritraumatic factors. The BIC value was also lowest for the fivefactor ESEM model; the five-factor model had a BIC value 157 points lower than the fourfactor model strongly supporting its statistical superiority. Based on these results and on the interpretability of the extracted factors, the five-factor ESEM model was deemed to be the optimal solution. The pattern of Geomin rotated factor loadings for the five peritraumatic experience factors in the ESEM model are shown in Table 2.

The 11 items from the Mental Defeat Questionnaire loaded strongly $(p<.001)$ onto the first factor, with weaker loadings for several other items reflecting lack of control or negative emotional reactions such as guilt and shame. The factor was labeled 'Mental Defeat'.

The strongest loadings on the second factor consisted of items from the Somatoform Peritraumatic Dissociation Questionnaire, and all of the items from this scale loaded at $p<$ .001. Most of the items from other scales loading strongly onto this factor were concerned with physical reactions, changes in bodily states, or changes in the person's sense of their body. This factor was labeled 'Somatoform Dissociation'.

Seven out of ten items from the Tonic Immobility Scale loaded at $p<.001$ on the third factor, with the strongest loading items reflecting an inability to move or respond in other ways. Items from other scales loading on this factor similarly reflected the freezing and tonic immobility responses as well as emotional states, predominantly fear for one's own safety and survival. The factor was labeled 'Immobility'. 
The strongest loadings on the fourth factor consisted of items from the Data-Driven Processing Scale, particularly those indicating the person felt cognitively overwhelmed or unable to process what was going on. All eight items from the DDPS loaded at $p<.001$ onto this factor. There were also notably strong factor loadings for items from other scales reflecting alterations in cognitive state such as detachment, disorientation, and confusion. This factor was labeled 'Cognitive Overload'.

Finally, ten out of 13 items from the Peritraumatic Distress Inventory loaded at $p<$ .001 onto the fifth factor. Items reflecting fear for one's own safety and survival that loaded highly on the fourth factor also loaded highly on this factor. What distinguished this factor were items from the PDI and other scales reflecting other emotional reactions, such as helplessness, sadness, anger, and fear for others. This factor was labeled 'Distress'.

\section{Prediction of PTSD Symptom Clusters}

The effects of each peritraumatic experience factor on the four PTSD symptom clusters are shown in Figure 1 (with the corresponding zero-order correlations in Supplementary Table 1$)$. The model fit the data well $\left(\chi^{2}(3052)=4044.67, p<.001 ; \mathrm{CFI}=\right.$ $.96 ;$ TLI $=.96 ;$ RMSEA $(90 \% \mathrm{CI})=.03(.03, .04)$; SRMR $=.06)$, and explained a significant $(p s<.001)$ proportion of variance in Intrusions $(55.6 \%)$, Avoidance $(29.1 \%)$, Negative Alterations in Cognition and Mood (50.0\%), and Alterations in Arousal and Reactivity (45.9\%). Mental Defeat and Somatoform Dissociation significantly predicted all four PTSD symptom clusters. Immobility significantly predicted Intrusions and Avoidance while Cognitive Overload significantly predicted all PTSD symptom clusters except Avoidance. Distress significantly predicted Negative Alterations in Cognition and Mood and Alterations in Arousal and Reactivity.

\section{Discussion}


This is the first study to assess the overall structure of commonly studied peritraumatic reactions and their association with PTSD symptom clusters in a large sample of individuals exposed to the same trauma. Five distinct factors emerged, consisting of Mental Defeat, Somatoform Dissociation, Immobility, Cognitive Overload, and Distress, that overlap with but are partly independent of existing scales. Two aspects of these results are particularly noteworthy. The first is the identification of the Cognitive Overload factor that although strongly related to existing well-recognized constructs does not correspond exactly to any one of them. This factor is primarily constituted from items measuring psychic dissociation on the Peritraumatic Dissociative Experiences Questionnaire and items from the Data-Driven Processing Scale. The overriding theme of the items from these two separate scales was a sense of disorientation and confusion, combined with an inability to apprehend and cognitively process events in the normal way. Whereas data-driven processing is a theoretical construct designed to account for how traumatic events may lead to PTSD, cognitive overload is a description of people's experience.

The second aspect concerns the experience of extreme fear. Fear of dying or perceived threat to life is a well-established risk factor for PTSD (Ozer et al., 2003). Our data suggested that it can occur both in the context of physiological reactions such as freezing and immobility and, along with other negative emotions such as sadness, horror, and concern for others, in the context of general emotional distress.

Our results correspond to those of several other studies that investigated the structure of individual peritraumatic measures. For example, although some authors reported a twofactor solution for the PDEQ contrasting "altered awareness" and "derealization" (Bryant et al., 2009; Sijbrandij et al., 2012), our finding that both types of item tended to load on a single factor indicating disrupted information-processing was more similar to early reports by Marmar et al. (1994, 1996). Our analyses also provided support for the three-factor structure 
of tonic immobility, where physical immobility, fear, and dissociation factors have been distinguished (Abrams, Carleton, Taylor, \& Asmundson, 2009). In our ESEM analysis some TIS items loaded on the Immobility factor, other items reflecting fear loaded on both the Immobility and Distress factors, and items reflecting dissociation loaded on the Somatoform Dissociation and Cognitive Overload factors.

Factor analyses of the PDI have generally resulted in inconsistent findings (Brunet et al., 2001; Rybojad, Aftyka, \& Samardakiewicz, 2018; Simeon, Greenberg, Knutelska, Schmeidler, \& Hollander, 2003). Our ESEM results confirm the likely heterogeneity of the PDI as there were some high loading items on each of the five factors. However, the majority of items were split between the Distress factor and the Mental Defeat factor, the latter reflecting guilt, shame, and loss of control. The life-threat items could be distinguished from the distress items by their loadings on both our Immobility and Distress factors.

In the current sample, Mental Defeat was one of two factors most highly associated with the four PTSD subscales, and was the best predictor of Negative Alterations in Cognition and Mood and of Alterations in Arousal and Reactivity. Somatoform Dissociation was the second factor most highly associated with the four PTSD subscales, and was the best predictor for the Avoidance subscale. This highlights the relevance of the construct which is attracting growing interest although it has to date received less attention than psychic aspects of dissociation which here had higher loadings on the Cognitive Overload factor. Of note, the PDI item measuring helplessness loaded strongly on the Cognitive Overload factor, echoing a specific association between helplessness and out-of-body-experiences previously noted by Reynolds and Brewin (1999).

Anecdotally, many participants in our study reported uncertainty over whether their immobility reaction was "psychological" or caused by the earthquake tremors. This could have made the measurement of immobility less accurate in the current sample. Despite this 
Immobility was associated with the Intrusions and Avoidance clusters. Previous research has shown that high levels of fear, as captured in the Immobility factor, are associated with more intrusions in PTSD (Reynolds \& Brewin, 1999). The role of immobility in predicting intrusive memories has also been studied in the trauma film paradigm. This exposes healthy participants to traumatic images and assesses how many intrusive images occur over the following days. Increased intrusions are associated with spontaneous reports of immobility while watching (Kuiling, Klaassen, \& Hagenaars, 2019) and with reductions in heart rate, an indicator of immobility (Chou, La Marca, Steptoe, \& Brewin, 2014; Holmes, Brewin, \& Hennessy, 2004).

In contrast, the Distress factor was associated with Negative Alterations in Cognition and Mood and Alterations in Arousal and Reactivity but not Intrusions or Avoidance. This echoes previous findings that PTSD symptoms from these clusters are part of a non-specific dysphoric element to the disorder that is distinct from intrusion and avoidance (Zelazny \& Simms, 2015). Although fear loads on the Distress factor its influence on intrusions may be counteracted by the numerous other emotions such as anger, sadness, and concern for others.

One of the limitations of the current research lies in the retrospective nature of peritraumatic reports. The existing evidence for the consistency of such reports over time is mixed (David, Akerib, Gaston, \& Brunet, 2010; Ouimette, Read, \& Brown, 2005; Zoellner, Sacks, \& Foa, 2001). In practice, detailed accounts of peritraumatic responding will always be retrospective, but could be accomplished sooner after the traumatic event and be followed up prospectively. Furthermore, we note that items from the same scale tended to load together and we cannot rule out the possibility that method effects (e.g., item ordering, shared wording, similar response formats) influenced the observed latent structure of peritraumatic distress. This limitation was impossible to avoid given the absence of a dedicated multifactor 
measure of peritraumatic response. Current findings can aid in the development of such a measure.

Other limitations include the use of purposive sampling but this was necessary since most participants were living in temporary, undocumented housing such as containers (see Massazza, Joffe, and Brewin, 2019, for more details). Again, it is unclear how sampling bias could affect the observed relationships between different peritraumatic responses or their relative ability to predict PTSD. Also, while the response rate was very high, we recognize that the current sample size may have resulted in the ESEM model being underpowered given the number of observed indicators. Finally, our conclusions are limited by the possible lack of generalizability to other types of trauma (van der Hart et al., 2008).

These findings confirm the importance for psychopathology of how information is apprehended and processed during trauma (Brewin, Gregory, Lipton, \& Burgess, 2010; Ehlers \& Clark, 2000) as well as of the variety of negative emotions involving the self and others that may occur during trauma (Massazza, Brewin, \& Joffe, in press; Vance et al., 2018). They also have implications for the conceptualization and operationalization of peritraumatic reactions, for interventions aimed at reducing the risk of PTSD following exposure, and for ensuring the wellbeing of individuals exposed to trauma more generally. In terms of measurement, our findings could be used to construct a new more comprehensive tool that would distinguish all five types of peritraumatic response. Further, understanding how people react during large scale disasters can assist the design of interventions such as disaster preparedness for survival (Joffe et al., 2019) and the planning of evacuations or drills in high risk communities (Drury, 2018). A more precise conceptualization of peritraumatic reactions is therefore a key research priority to safeguard the wellbeing, both mental and physical, of survivors. 


\section{Acknowledgements}

The authors would like to thank the municipality and health center of Amatrice and the psychiatric services of Rieti for their practical support in conducting the study, in particular Antonella Fabiano, Simone Lodovisi, Anna Desantis, Gianna Petrocco, Fabrizio Borrello, Domenica Tomassoni, Gabriella Nobili, and Oriana D’Emidio. We would also like to thank Jean-Baptiste Pingault and Jack Andrews for their support in the conceptualization of the analysis. Most importantly, our most heartfelt gratitude goes to the participants. Finally, we would like to thank the Economic and Social Research Council for their financial support. 


\section{References}

Abrams, M. P., Carleton, R. N., \& Asmundson, G. J. G. (2012). Tonic immobility does not uniquely predict posttraumatic stress symptom severity. Psychological TraumaTheory Research Practice and Policy, 4, 278-284. doi:10.1037/a0023272

Abrams, M. P., Carleton, R. N., Taylor, S., \& Asmundson, G. J. G. (2009). Human tonic immobility: Measurement and correlates. Depression and Anxiety, 26, 550-556. doi:10.1002/da.20462

Adams, R. E., \& Boscarino, J. A. (2011). A structural equation model of perievent panic and posttraumatic stress disorder after a community disaster. Journal of Traumatic Stress, 24, 61-69. doi:10.1002/jts.20603

American Psychiatric Association. (1994). Diagnostic and statistical manual of mental disorders (4th ed.). Washington, DC: American Psychiatric Association.

American Psychiatric Association. (2013). Diagnostic and statistical manual of mental disorders (5th ed.). Washington, DC: American Psychiatric Association.

Andrews, B., Brewin, C. R., Rose, S., \& Kirk, M. (2000). Predicting PTSD symptoms in victims of violent crime: The role of shame, anger, and childhood abuse. Journal of Abnormal Psychology, 109, 69-73. doi:10.1037/0021-843x.109.1.69

Asparouhov, T., \& Muthén, B. (2009). Exploratory structural equation modeling. Structural Equation Modeling, 16, 397-438. doi:10.1080/10705510903008204

Birmes, P., Brunet, A., Benoit, M., Defer, S., Hatton, L., Sztulman, H., \& Schmitt, L. (2005). Validation of the Peritraumatic Dissociative Experiences Questionnaire self-report version in two samples of French-speaking individuals exposed to trauma. European Psychiatry, 20, 145-151. doi:10.1016/j.eurpsy.2004.06.033

Bovin, M. J., \& Marx, B. P. (2011). The importance of the peritraumatic experience in defining traumatic stress. Psychological Bulletin, 137, 47-67. doi:10.1037/a0021353 
Bovin, M. J., Marx, B. P., Weathers, F. W., Gallagher, M. W., Rodriguez, P., Schnurr, P. P., \& Keane, T. M. (2016). Psychometric properties of the PTSD Checklist for Diagnostic and Statistical Manual of Mental Disorders-Fifth Edition (PCL-5) in veterans. Psychological Assessment, 28, 1379-1391. doi:10.1037/pas0000254

Brewin, C. R., Andrews, B., \& Rose, S. (2000). Fear, helplessness, and horror in posttraumatic stress disorder: Investigating DSM-IV criterion A2 in victims of violent crime. Journal of Traumatic Stress, 13, 499-509. doi:10.1023/a:1007741526169

Brewin, C. R., Gregory, J. D., Lipton, M., \& Burgess, N. (2010). Intrusive images in psychological disorders: Characteristics, neural mechanisms, and treatment implications. Psychological Review, 117, 210-232. doi:10.1037/a0018113

Brunet, A., Weiss, D. S., Metzler, T. J., Best, S. R., Neylan, T. C., Rogers, C., . . Marmar, C. R. (2001). The peritraumatic distress inventory: A proposed measure of PTSD criterion A2. American Journal of Psychiatry, 158, 1480-1485. doi:10.1176/appi.ajp.158.9.1480

Bryant, R. A. (2007). Does dissociation further our understanding of PTSD? Journal of Anxiety Disorders, 21, 183-191. doi:10.1016/j.janxdis.2006.09.012

Bryant, R. A., Brooks, R., Silove, D., Creamer, M., O'Donnell, M., McFarlane, A. C., \& Marmar, C. R. (2009). The latent structure of the Peritraumatic Dissociative Experiences Questionnaire. Journal of Traumatic Stress, 22, 69-73. doi:10.1002/jts.20388

Bui, E., Brunet, A., Allenou, C., Camassel, C., Raynaud, J.-P., Claudet, I., . . Birmes, P. (2010). Peritraumatic reactions and posttraumatic stress symptoms in school-aged children victims of road traffic accident. General Hospital Psychiatry, 32, 330-333. doi:10.1016/j.genhosppsych.2010.01.014 
Bui, E., Brunet, A., Olliac, B., Very, E., Allenou, C., Raynaud, J. P., . . Birmes, P. (2011). Validation of the Peritraumatic Dissociative Experiences Questionnaire and Peritraumatic Distress Inventory in school-aged victims of road traffic accidents. European Psychiatry, 26, 108-111. doi:10.1016/j.eurpsy.2010.09.007

Cardeña, E. (1994). The domain of dissociation. In S. J. Lynn \& J. W. Rhue (Eds.), Dissociation: Clinical and theoretical perspectives (pp. 15-31). New York: Guilford.

Chen, F., Curran, P. J., Bollen, K. A., Kirby, J., \& Paxton, P. (2008). An empirical evaluation of the use of fixed cutoff points in RMSEA test statistic in structural equation models. Sociological Methods \& Research, 36, 462-494. doi:10.1177/0049124108314720

Chou, C.-Y., La Marca, R., Steptoe, A., \& Brewin, C. R. (2014). Heart rate, startle response, and intrusive trauma memories. Psychophysiology, 51, 236-246. doi:10.1111/psyp. 12176

David, A.-C., Akerib, V., Gaston, L., \& Brunet, A. (2010). Consistency of retrospective reports of peritraumatic responses and their relation to PTSD diagnostic status. Journal of Traumatic Stress, 23, 599-605. doi:10.1002/jts.20566

Drury, J. (2018). The role of social identity processes in mass emergency behaviour: An integrative review. European Review of Social Psychology, 29, 38-81. doi:10.1080/10463283.2018.1471948

Dunmore, E., Clark, D. M., \& Ehlers, A. (1999). Cognitive factors involved in the onset and maintenance of posttraumatic stress disorder (PTSD) after physical or sexual assault. Behaviour Research and Therapy, 37, 809-829. doi:10.1016/s0005-7967(98)00181-8

Dunmore, E., Clark, D. M., \& Ehlers, A. (2001). A prospective investigation of the role of cognitive factors in persistent Posttraumatic Stress Disorder (PTSD) after physical or sexual assault. Behaviour Research and Therapy, 39, 1063-1084. doi:10.1016/s00057967(00)00088-7 
Ehlers, A., \& Clark, D. M. (2000). A cognitive model of posttraumatic stress disorder. Behaviour Research and Therapy, 38, 319-345.

Ehlers, A., Maercker, A., \& Boos, A. (2000). Posttraumatic stress disorder following political imprisonment: The role of mental defeat, alienation, and perceived permanent change. Journal of Abnormal Psychology, 109, 45-55. doi:10.1037/0021-843x.109.1.45

Ehring, T., Ehlers, A., \& Glucksman, E. (2008). Do cognitive models help in predicting the severity of posttraumatic stress disorder, phobia, and depression after motor vehicle accidents? A prospective longitudinal study. Journal of Consulting and Clinical Psychology, 76, 219-230. doi:10.1037/0022-006x.76.2.219

Fikretoglu, D., Brunet, A., Best, S., Metzler, T., Delucchi, K., Weiss, D. S., . . Marmar, C. (2006). The relationship between peritraumatic distress and peritraumatic dissociation. Journal of Nervous and Mental Disease, 194, 853-858. doi:10.1097/01.nmd.0000244563.22864.f1

Flora, D. B., \& Curran, P. J. (2004). An empirical evaluation of alternative methods of estimation for confirmatory factor analysis with ordinal data. Psychological Methods, 9, 466-491. doi:10.1037/1082-989x.9.4.466

Forsyth, J. P., Marx, B., Fusé, T. M. K., Heidt, J., \& Gallup, G. G. J. (2000). The Tonic Immobility Scale: Albany, NY: Authors.

Freeman, D., Thompson, C., Vorontsova, N., Dunn, G., Carter, L. A., Garety, P., .. . Ehlers, A. (2013). Paranoia and post-traumatic stress disorder in the months after a physical assault: a longitudinal study examining shared and differential predictors. Psychological Medicine, 43, 2673-2684. doi:10.1017/s003329171300038x

Fusé, T., Forsyth, J. P., Marx, B., Gallup, G. G., \& Weaver, S. (2007). Factor structure of the Tonic Immobility Scale in female sexual assault survivors: An exploratory and 
confirmatory factor analysis. Journal of Anxiety Disorders, 21, 265-283. doi:10.1016/j.janxdis.2006.05.004

Gallup, G. G., Jr., \& Rager, D. R. (1996). Tonic immobility as a model of extreme states of behavioral inhibition: Issues of methodology and measurement. In P. R. Sanberg, K. P. Ossenkopp, \& M. Kavaliers (Eds.), Motor activity and movement disorders: Research issues and applications (pp. 57-80). New York: Springer.

Gorman, K. R., Engel-Rebitzer, E., Ledoux, A. M., Bovin, M. J., \& Marx, B. P. (2016). Peritraumatic experience and traumatic stress. In C. Martin, V. Preedy, \& V. Patel (Eds.), Comprehensive guide to post-traumatic stress disorders (pp. 907-924). Cham: Springer.

Hagenaars, M. A. (2016). Tonic immobility and PTSD in a large community sample. Journal of Experimental Psychopathology, 7, 246-260. doi:10.5127/jep.051915

Hagenaars, M. A., van Minnen, A., \& Hoogduin, K. A. L. (2007). Peritraumatic psychological and somatoform dissociation in predicting PTSD symptoms - A prospective study. Journal of Nervous and Mental Disease, 195, 952-954. doi:10.1097/NMD.0b013e3181594810

Halligan, S. L., Clark, D. M., \& Ehlers, A. (2002). Cognitive processing, memory, and the development of PTSD symptoms: two experimental analogue studies. Journal of Behavior Therapy and Experimental Psychiatry, 33, 73-89. doi:10.1016/s00057916(02)00014-9

Halligan, S. L., Michael, T., Clark, D. M., \& Ehlers, A. (2003). Posttraumatic stress disorder following assault: The role of cognitive processing, trauma memory, and appraisals. Journal of Consulting and Clinical Psychology, 71, 419-431. doi:10.1037/0022006x.71.3.419 
Holmes, E. A., Brewin, C. R., \& Hennessy, R. G. (2004). Trauma films, information processing, and intrusive memory development. Journal of Experimental PsychologyGeneral, 133, 3-22. doi:10.1037/0096-3445.133.1.3

Hu, L.-T., \& Bentler, P. M. (1999). Cutoff criteria for fit indexes in covariance structure analysis: Conventional criteria versus new alternatives. Structural Equation Modeling, 6, 1-55. doi:10.1080/10705519909540118

Istituto Nazionale di Statistica. (2016). Popolazione per età, sesso e stato civile 2016 (Amatrice). Retrieved 10 February 2020 from https://www.tuttitalia.it/lazio/82amatrice/statistiche/

Joffe, H., Potts, H. W. W., Rossetto, T., Dogulu, C., Gul, E., \& Perez-Fuentes, G. (2019). The Fix-it face-to-face intervention increases multihazard household preparedness crossculturally. Nature Human Behaviour, 3, 453-461. doi:10.1038/s41562-019-05630

Kalaf, J., Freire Coutinho, E. S., Pereira Vilete, L. M., Luz, M. P., Berger, W., Mendlowicz, M., . . Figueira, I. (2017). Sexual trauma is more strongly associated with tonic immobility than other types of trauma - A population based study. Journal of Affective Disorders, 215, 71-76. doi:10.1016/j.jad.2017.03.009

Kalaf, J., Vilete, L. M. P., Volchan, E., Fiszman, A., Freire Coutinho, E. S., Andreoli, S. B., . . Figueira, I. (2015). Peritraumatic tonic immobility in a large representative sample of the general population: association with posttraumatic stress disorder and female gender. Comprehensive Psychiatry, 60, 68-72. doi:10.1016/j.comppsych.2015.04.001

Kannis-Dymand, L., Carter, J. D., Lane, B. R., \& Innes, P. (2019). The relationship of peritraumatic distress and dissociation with beliefs about memory following natural disasters. Australian Psychologist, 54, 311-321. doi:10.1111/ap.12377 
Kleim, B., Ehlers, A., \& Glucksman, E. (2012). Investigating cognitive pathways to psychopathology: Predicting depression and posttraumatic stress disorder from early responses after assault. Psychological Trauma-Theory Research Practice and Policy, 4, 527-537. doi:10.1037/a0027006

Kuiling, J. M. E., Klaassen, F., \& Hagenaars, M. A. (2019). The role of tonic immobility and control in the development of intrusive memories after experimental trauma. Memory, 27, 772-779. doi:10.1080/09658211.2018.1564331

Lensvelt-Mulders, G., van der Hart, O., van Ochten, J. M., van Son, M. J. M., Steele, K., \& Breeman, L. (2008). Relations among peritraumatic dissociation and posttraumatic stress: A meta-analysis. Clinical Psychology Review, 28, 1138-1150. doi:10.1016/j.cpr.2008.03.006

March, J. S. (1993). What constitutes a stressor? In J. R. T. Davidson \& E. B. Foa (Eds.), Posttraumatic stress disorder (pp.37-54). Washington, DC: American Psychiatric Press.

Marmar, C. R., Metzler, T. J., \& Otte, C. (2004). The Peritraumatic Dissociative Experiences Questionnaire. In J. P. Wilson \& T. M. Keane (Eds.), Assessing psychological trauma and PTSD (2nd ed., pp. 144-167). New York: Guilford.

Marmar, C. R., Weiss, D. S., \& Metzler, T. J. (1997). The Peritraumatic Dissociative Experiences questionnaire In J. P. Wilson \& T. M. Keane (Eds.), Assessing psychological trauma and PTSD (1st ed., pp. 412-428). New York: Guilford.

Marmar, C. R., Weiss, D. S., Metzler, T. J., Ronfeldt, H. M., \& Foreman, C. (1996). Stress responses of emergency services personnel to the Loma Prieta earthquake interstate 880 freeway collapse and control traumatic incidents. Journal of Traumatic Stress, 9, 63-85. doi:10.1002/jts.2490090107 
Marmar, C. R., Weiss, D. S., Schlenger, W. E., Fairbank, J. A., Jordan, B. K., Kulka, R. A., \& Hough, R. L. (1994). Peritraumatic dissociation and posttraumatic stress in male Vietnam theatre veterans. American Journal of Psychiatry, 151, 902-907.

Marx, B. P., Forsyth, J. P., Gallup, G. G., Fusé, T., \& Lexington, J. M. (2008). Tonic immobility as an evolved predator defense: Implications for sexual assault survivors. Clinical Psychology-Science and Practice, 15, 74-90. doi:10.1111/j.14682850.2008.00112.x

Massazza, A., Brewin, C. R., \& Joffe, H. (in press). Feelings, thoughts, and behaviors during disaster. Qualitative Health Research.

Massazza, A., Joffe, H., \& Brewin, C. R. (2019). Earthquakes, attributions, and psychopathology: a study in a rural community. European Journal of Psychotraumatology, 10. doi:10.1080/20008198.2019.1661813

Moss, K. M., Simcock, G., Cobham, V., Kildea, S., Elgbeili, G., Laplante, D. P., \& King, S. (2017). A potential psychological mechanism linking disaster-related prenatal maternal stress with child cognitive and motor development at 16 months: The QF2011 Queensland Flood study. Developmental Psychology, 53, 629-641. doi:10.1037/dev0000272

Muthén, L. K., \& Muthén, B. O. (2017). Mplus user's guide (8th ed.): Los Angeles, CA: Muthén \& Muthén.

Nijenhuis, E. R. S., \& van der Hart, O. (1998). The Somatic Dissociation Questionnaire Peritraumatic (SDQ-P): Unpublished measure.

Nijenhuis, E. R. S., van der Hart, O., Kruger, K., \& Steele, K. (2004). Somatoform dissociation, reported abuse and animal defence-like reactions. Australian and New Zealand Journal of Psychiatry, 38, 678-686. doi:10.1080/j.1440-1614.2004.01441.x 
Nijenhuis, E. R. S., van Engen, A., Kusters, I., \& van der Hart, O. (2001). Peritraumatic somatoform and psychological dissociation in relation to recall of childhood sexual abuse. Journal of Trauma \& Dissociation, 2, 49-68. doi:10.1300/J229v02n03_04

Nijenhuis, E. R. S., Vanderlinden, J., \& Spinhoven, P. (1998). Animal defensive reactions as a model for trauma-induced dissociative reactions. Journal of Traumatic Stress, 11, 243-260. doi:10.1023/a:1024447003022

Otis, C., Marchand, A., \& Courtois, F. (2012). Peritraumatic dissociation as a mediator of peritraumatic distress and PTSD: A retrospective, cross-sectional study. Journal of Trauma \& Dissociation, 13, 469-477. doi:10.1080/15299732.2012.670870

Ouimette, P., Read, J., \& Brown, P. J. (2005). Consistency of retrospective reports of DSMIV criterion A traumatic stressors among substance use disorder patients. Journal of Traumatic Stress, 18, 43-51. doi:10.1002/jts.20009

Ozer, E. J., Best, S. R., Lipsey, T. L., \& Weiss, D. S. (2003). Predictors of posttraumatic stress disorder and symptoms in adults: A meta-analysis. Psychological Bulletin, 129, 52-73. doi:10.1037/0033-2909.129.1.52

Raftery, A. E. (1995). Bayesian model selection in social research. Sociological Methodology, 25, 111-163. doi:10.2307/271063

Reynolds, M., \& Brewin, C. R. (1999). Intrusive memories in depression and posttraumatic stress disorder. Behaviour Research and Therapy, 37, 201-215. doi:10.1016/s00057967(98)00132-6

Rybojad, B., Aftyka, A., \& Samardakiewicz, M. (2018). Factor analysis and validity of the Polish version of the Peritraumatic Distress Inventory in mothers of seriously ill children. Journal of Clinical Nursing, 27, 3945-3952. doi:10.1111/jocn.14597

Sijbrandij, M., Engelhard, I. M., Opmeer, B. C., van de Schoot, R., Carlier, I. V. E., Gersons, B. P. R., \& Olff, M. (2012). The structure of peritraumatic dissociation: A cross 
validation in clinical and nonclinical samples. Journal of Traumatic Stress, 25, 475479. doi: $10.1002 /$ jts. 21716

Simeon, D., Greenberg, J., Knutelska, M., Schmeidler, J., \& Hollander, E. (2003). Peritraumatic reactions associated with the World Trade Center disaster. American Journal of Psychiatry, 160, 1702-1705. doi:10.1176/appi.ajp.160.9.1702

Solomon, Z., Laor, N., \& McFarlane, A. C. (1996). Acute posttraumatic reactions in soldiers and civilians. In B. A. van der Kolk, A. C. McFarlane, \& L. Weisaeth (Eds.), Traumatic stress (pp. 102-114). New York: Guilford.

Sveen, J., Bondjers, K., \& Willebrand, M. (2016). Psychometric properties of the PTSD Checklist for DSM-5: a pilot study. European Journal of Psychotraumatology, 7. doi:10.3402/ejpt.v7.30165

Tanaka, J. S. (1987). How big is big enough - Sample size and goodness of fit in structural equation models with latent variables. Child Development, 58, 134-146. doi:10.1111/j.1467-8624.1987.tb03495.x

Thomas, E., Saumier, D., \& Brunet, A. (2012). Peritraumatic distress and the course of posttraumatic stress disorder symptoms: A meta-analysis. Canadian Journal of Psychiatry, 57, 122-129. doi:10.1177/070674371205700209

van der Hart, O., Nijenhuis, E., Steele, K., \& Brown, D. (2004). Trauma-related dissociation: conceptual clarity lost and found. Australian and New Zealand Journal of Psychiatry, 38, 906-914. doi:10.1080/j.1440-1614.2004.01480.x

van der Hart, O., van Ochten, J. M., van Son, M. J. M., Steele, K., \& Lensvelt-Mulders, G. (2008). Relations among peritraumatic dissociation and posttraumatic stress: A critical review. Journal of Trauma \& Dissociation, 9, 481-505. doi:10.1080/15299730802223362 
Vance, M. C., Kovachy, B., Dong, M., \& Bui, E. (2018). Peritraumatic distress: A review and synthesis of 15 years of research. Journal of Clinical Psychology, 74, 1457-1484. doi:10.1002/jclp.22612

Weathers, F. W., Litz, B. T., Keane, T. M., Palmieri, P. A., Marx, B. P., \& Schnurr, P. P. (2013). The PTSD Checklist for DSM-5 (PCL-5): Scale available from the National Center for PTSD at www.ptsd.va.gov.

Wilker, S., Kleim, B., Geiling, A., Pfeiffer, A., Elbert, T., \& Kolassa, I.-T. (2017). Mental defeat and cumulative trauma experiences predict trauma-related psychopathology: Evidence from a postconflict population in Northern Uganda. Clinical Psychological Science, 5, 974-984. doi:10.1177/2167702617719946

Zelazny, K., \& Simms, L. J. (2015). Confirmatory factor analyses of DSM-5 posttraumatic stress disorder symptoms in psychiatric samples differing in Criterion A status. Journal of Anxiety Disorders, 34, 15-23. doi:10.1016/j.janxdis.2015.05.009

Zoellner, L. A., Sacks, M. B., \& Foa, E. B. (2001). Stability of emotions for traumatic memories in acute and chronic PTSD. Behaviour Research and Therapy, 39, 697-711. doi:10.1016/s0005-7967(00)00050-4 


\section{Table 1}

ESEM Model Fit Results

\begin{tabular}{|c|c|c|c|c|c|c|c|c|c|}
\hline & $\chi^{2}$ & df & CFI & TLI & RMSEA & $90 \% \mathrm{CI}$ & SRMR & $\Delta$ TLI K-1 factor & $\mathrm{BIC}$ \\
\hline One factor & 6328 & 3315 & .876 & .873 & .054 & $.052, .056$ & .088 & -- & 81880 \\
\hline Two factors & 5420 & 3252 & .911 & .907 & .047 & $.044, .049$ & .079 & .034 & 81292 \\
\hline Three factors & 4851 & 3190 & .932 & .927 & .041 & $.039, .043$ & .070 & .020 & 80972 \\
\hline Four factors & 4420 & 3129 & .947 & .942 & .037 & $.034, .039$ & .063 & .015 & 80736 \\
\hline Five factors & 4112 & 3069 & .957 & .952 & .033 & $.031, .036$ & .058 & .010 & 80591 \\
\hline Six factors & 3918 & 3010 & .963 & .958 & .031 & $.028, .034$ & .055 & .006 & 80614 \\
\hline Seven factors & 3774 & 2952 & .966 & .961 & .030 & $.027, .033$ & .053 & .003 & 80633 \\
\hline
\end{tabular}

Note. $\chi^{2}=$ chi-square test; $\mathrm{df}=$ degrees of freedom; CFI = Comparative Fit Index; TLI = Tucker-Lewis Index; RMSEA = Root Mean Square

Error of Approximation; SRMR = Standardized Root Mean Residual; $\Delta$ TLI K-1 factor $=$ Change in TLI value between model and model with one less factor; BIC = Bayesian Information Criterion (estimated via the ML estimator); All $\chi^{2}$ results are statistically significant $(p<.001)$. Best fitting models are in bold. 
Table 2

Standardized Factor Loadings for the Five-Factor ESEM Solution

\begin{tabular}{|c|c|c|c|c|c|}
\hline & $\begin{array}{r}\text { Mental } \\
\text { Defeat (F1) }\end{array}$ & $\begin{array}{r}\text { Somatoform } \\
\text { Dissociation } \\
(\mathrm{F} 2) \\
\end{array}$ & $\begin{array}{r}\text { Immobility } \\
\text { (F3) }\end{array}$ & $\begin{array}{r}\text { Cognitive } \\
\text { Overload (F4) }\end{array}$ & $\begin{array}{r}\text { Distress } \\
(\mathrm{F} 5)\end{array}$ \\
\hline MDQ-1 "I lost any will-power" & .51 & -.00 & .17 & .19 & .08 \\
\hline $\begin{array}{l}\text { MDQ-2 "I didn't care what happened to me } \\
\text { anymore" }\end{array}$ & .62 & .14 & -.10 & -.00 & .02 \\
\hline MDQ-3 "I felt completely defeated" & .72 & -.06 & .12 & -.02 & .15 \\
\hline MDQ-4 "I no longer felt like a human being" & .59 & .25 & .08 & .05 & .03 \\
\hline MDQ-5 "In my mind, I gave up" & .77 & -.07 & .08 & .13 & -.02 \\
\hline MDQ-6 "I felt destroyed as a person" & .63 & -.01 & .03 & .18 & .18 \\
\hline MDQ-7 "I wanted to die" & .73 & .08 & -.08 & .11 & .04 \\
\hline MDQ-8 "I lost any inner resistance" & .59 & .01 & .11 & .19 & .05 \\
\hline MDQ-9 "I felt like an object" & .68 & .06 & .02 & .04 & -.01 \\
\hline $\begin{array}{l}\text { MDQ-10 "I felt completely at the mercy of other } \\
\text { people or the situation" }\end{array}$ & .61 & .00 & -.02 & .00 & .09 \\
\hline $\begin{array}{l}\text { MDQ-11 "I felt completely humiliated and lost any } \\
\text { sense of inner dignity" }\end{array}$ & .73 & .24 & -.12 & .07 & -.06 \\
\hline $\begin{array}{l}\text { SDQ-P-1 "It felt as if my body, or parts of it, was } \\
\text { paralysed" }\end{array}$ & .18 & .26 & .71 & -.02 & -.02 \\
\hline $\begin{array}{l}\text { SDQ-P-2 "My visual field was smaller than usual (it } \\
\text { felt as if I was looking through a tunnel or could just } \\
\text { see a section of an area)" }\end{array}$ & -.10 & .59 & .23 & .16 & -.11 \\
\hline $\begin{array}{l}\text { SDQ-P-3 "It felt as if my body, or parts of it, } \\
\text { disappeared" }\end{array}$ & .25 & .64 & .15 & .07 & -.05 \\
\hline
\end{tabular}


SDQ-P-4 "I felt temporarily paralysed or stiff"

SDQ-P-5 "It felt as if my body, or parts of it, were numb"

SDQ-P-6 "My sense of taste diminished or was absent"

SDQ-P-7 "I crouched and automatically did not move, it was involuntary and not because I was physically restrained"

SDQ-P-8 "I felt like I had to vomit"

SDQ-P-9 "I made goal-directed movements that I did not control myself (e.g. trying to grab something)"

SDQ-P-10 "I did not physically manage to eat and drink, although food and drinks were available and not forbidden"

SDQ-P-11 "I completely lost my appetite and thirst while I was hungry or thirsty before"

PDEQ-1 "I had moments of losing track of what was going on. I "blanked out" or "spaced out" or in some way felt that I was not part of what was going on" PDEQ-2 "I found that I was on "automatic pilot". I ended up doing things that I later realized I hadn't actively decided to do"

PDEQ-3 "My sense of time changed. Things seemed to be happening in slow motion"

PDEQ-4 "What was happening seemed unreal to me, like I was in a dream, or watching a movie or play"

PDEQ-5 "I felt as though I were spectator watching what was happening to me, as if I were floating above the scene or observing it as an outsider"
.33

.61 
PDEQ-6 "There were moments when my sense of body seemed distorted or changed. I felt disconnected from my own body, or it was unusually

large or small"

PDEQ-7 "I felt as though things that were actually happening to others were happening to me- like I was in danger when I really wasn't"

PDEQ-8 "I was surprised to find afterwards that a lot of things happened at the time that I was not aware of, especially things I ordinarily would have noticed" PDEQ-9 "I felt confused; that is, there were

moments when I had difficulty making sense of what was happening"

PDEQ-10 "I felt disoriented; that is, there were

moments when I felt uncertain about where I was or what time it was"

TIS-1 "Rate the degree to which you froze or felt paralysed during your most recent experience"

TIS-2 "Rate the degree to which you were unable to move even though not restrained"

TIS-3 "Rate the degree to which your body was trembling/shaking during the event"

TIS-4 "Rate the degree to which you were unable to call out or scream during the event"

TIS-5 "Rate the degree to which you felt numb or no pain during the event"

TIS-6 "Rate the extent to which you felt cold during the event"

TIS-7 "Rate the event to which you felt feelings of fear/panic during the event"

TIS-8 "Rate the extent to which you feared for your life or felt as though you were going to die"
.45 
The Structure of Peritraumatic Reactions 36

TIS-9 "Rate the extent to which you felt detached from yourself during the event"

.08

TIS-10 "Rate the extent to which you felt detached

from what was going on around you"

PDI-1 "I felt helpless"

PDI-2 "I felt sadness and grief"

PDI-3 "I felt frustrated or angry"

PDI-4 "I felt afraid for my own safety"

PDI-5 "I felt guilty"

PDI-6 "I felt ashamed of my emotional reactions"

PDI-7 "I felt worried about the safety of others"

PDI-8 "I had the feeling I was about to lose control

of my emotions"

PDI-9 "I had difficulty controlling my bowel and

bladder"

PDI-10 "I was horrified by what I saw"

PDI-11 "I had physical reactions like sweating,

shaking, and my heart pounding"

PDI-12 "I felt I might pass out"

PDI-13 "I thought I might die"

DDPS- 1 "I couldn't really take it all in"

DDPS-2 "I did not fully understand what was going on"

DDPS-3 "It was just like a stream of unconnected impressions following each other"

DDPS-4 "I could not think clearly"

DDPS-5 "I was overwhelmed by sensations and couldn't put everything together"
.42

.33

$-.20$

$-.12$

.01

$-.09$

.22

.27

$-.09$

.14

.37

.12

.24

.30

$-.04$

$-.04$

$-.02$

$-.04$

$-.02$

$-.07$
.28

.20

.09

.03

$-.08$

.39

$-.10$

.08

$-.05$

.17

.08

.05

.26

.29

.44

.03

$-.01$

.04

.05

$-.01$
.31

$-.08$

$.49-.21$

.37

.40

$.20 \quad .46$

$-.03 \quad .41$

$.05 \quad \mathbf{. 5 8}$

$\begin{array}{ll}-.09 & .05\end{array}$

$-.11 \quad-.02$

$.02 \quad .51$

$.15 \quad .21$

$-.03 \quad .07$

$.21 \quad .30$

$.17 \quad .43$

$.15 \quad .34$

$-.13 \quad .62$

$\begin{array}{ll}.83 & .09\end{array}$

$.94-.00$

$\mathbf{8 1} \quad .14$

$.86 \quad .03$

$\begin{array}{ll}.87 & .10\end{array}$ 
The Structure of Peritraumatic Reactions 37

DDPS-6 "I was confused and could not fully make sense of what was happening"

.18

.14

DDPS-7 "My mind was fully occupied with what I saw, heard, smelled and felt"

DDPS-8 "My mind was full of impressions and my reactions to them"

Peritraumatic; PDEQ = Peritraumatic Dissociative Experiences Questionnaire; TIS = Tonic Immobility Scale; PDI = Peritraumatic Distress

Inventory; DDPS = Data-Driven Processing Scale
.44

.46

$-.08$
.32

$\mathbf{8 8} \quad .02$

$\begin{array}{llll}.06 & -.08 & \mathbf{4 6} & \mathbf{3 2}\end{array}$

$\mathrm{SDQ}-\mathrm{P}=$ Somatic Dissociation Questionnaire - 


\section{Figure 1}

Simplified Description of the Effects of each Peritraumatic Factor on the Four PTSD Symptom Clusters.

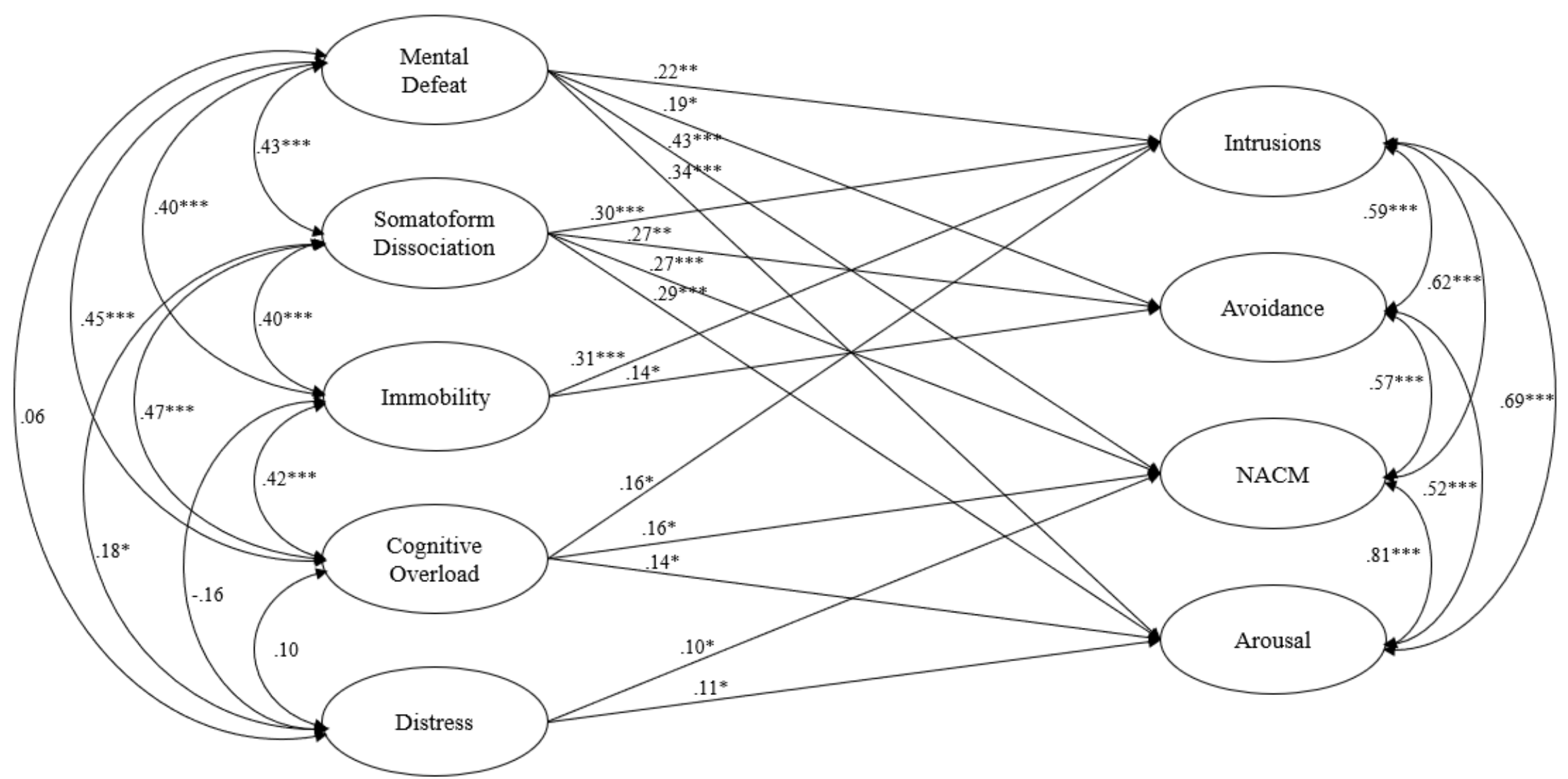

Note. Only statistically significant standardized beta values are depicted. Factor loadings are not depicted for the sake of simplicity. ${ }^{*} p<.05$, $* * p<.01, * * * p<.001$. 